\title{
Equídeos infectados por Leishmania (Leishmania) Infantum na área endêmica de Teresina, Piauí, Brasil*
}

\section{Equines infected by Leishmania (Leishmania) Infantum in the endemic area of Teresina, Piauí, Brazil}

\author{
Nilton Andrade Magalhães, ${ }^{* *}$ Francisco Humberto da Silva Ribeiro, ${ }^{* *}$ Eláine Gonçalves Oliveira, ${ }^{* *}$ Aline Pereira Martins, ${ }^{* *}$ \\ José Arnaldo de Sá Junior, ${ }^{* *}$ Lucilene Santos Silva, ${ }^{* *}$ Cristian Francisco de Carvalho Oliveira, ${ }^{* *}$ Maria das Graças Prianti, ${ }^{* *}$ \\ Diego Peres Alonso, ${ }^{* * * *}$ Francisco Assis Lima Costa***
}

\begin{abstract}
Resumo
Objetivou-se com este estudo pesquisar infecção natural de equídeos por Leishmania sp em área endêmica de leishmaniose tegumentar americana de Teresina, Piauí, Brasil. As leishmanioses são causadas por protozoário hemoflagelado, intracelular integrante do gênero Leishmania. Clinicamente observa-se uma variedade de sinais desde lesões cutâneas até formas viscerotrópicas que são mais graves e potencialmente fatais. Constituem grande problema de saúde pública mundial. O cão é considerado o principal reservatório doméstico de leishmaniose visceral americana (LVA). No peridomicílio de moradias rurais, os equídeos, embora com menor relevância que os canídeos, podem se transformar em importante hospedeiro para este parasito. Coletou-se sangue periférico de 42 equídeos para pesquisa de DNA de leishmânia spp através da técnica de "nested" reação em cadeia de polimerase (PCR) com oligonucleotídeos flanqueando a região ribossomal internal transcribed spacer 1 (ITS'1). A confirmação da espécie foi realizada pela digestão do produto amplificado com enzima de restrição Hae III. Os animais não apresentavam sinal clínico sugestivo de nenhuma patologia, entretanto 21 (50\%) foram PCR positivos para leishmaniose (14 equinos, quatro asininos e três muares). A digestão do produto da "nested" PCR permitiu identificar sequências de DNA de Leishmania (Leishmania) infantum, caracterizando a infecção como leishmaniose visceral americana (LVA). A presença de equídeos infectados com Leishmania (Leishmania) infantum sugere sua participação no ciclo de transmissão da leishmaniose visceral em Teresina, Piauí, Brasil.
\end{abstract}

Palavras-chave: endemia, Leishmaniose visceral, PCR.

\begin{abstract}
This study aims to research natural Leishmania sp equine infection in an endemic American Tegumentary Leishmaniasis area of Teresina City, Piauí State, Brazil. Leishmania are caused by intracellular hemoflagellate protozoa of the gender Leishmania. Clinically we can observe a variety of signals since cutaneous injuries until viscerotropic types which are more severe and potentially fatal. They constitute a great worldwide public health problem. The dog is considered the main domestic reservoir of American Visceral Leishmaniasis (AVL). In the peridomicile of rural abodes, the equines, although with less relevance than canines, may become an important host for this parasite. Peripheral blood was collected from 42 equines for DNA research of leishmania spp through the technique of "nested" PCR with oligonucleotides flanking the region ITS'1. The confirmation of the species was performed by the digestion of the amplified product with restriction enzyme Hae III. The animals did not present any suggestive clinical pathology signal, however, 21 (50\%) were PCR positive for Leishmaniasis (14 equines, four donkeys and three mules). The digestion of the product from "nested" PCR permitted to identify DNA sequences of Leishmania (Leishmania) infantum, characterizing the infection as American Visceral Leishmaniasis (AVL). The presence of infected equines with Leishmania (Leishmania) infantun suggests their participation in the cycle of visceral Leishmaniasis transmission in Teresina City, Piauí State, Brazil.
\end{abstract}

Keywords: endemics, visceral Leishmaniasis, PCR.

\section{Introdução}

As leishmanioses são causadas por uma grande variedade de parasitos intracelulares obrigatórios do gênero Leishmania. São doenças de transmissão vetorial havendo várias espécies e subespécies de dípteros flebotomíneos vetores de Leishmania
(Killick-Kendrick; Rioux, 2002). O cão é considerado o principal reservatório doméstico do parasito (OPAS, 2009), sendo que um dos principais métodos de controle é a eutanásia deste animal soropositivo. Contudo o que tem se observado, é que a eutanásia de cães sorologicamente positivos não tem alcançado resultados satisfatórios (Dantas-Torres et al., 2012), sugerindo

*Recebido em 25 de julho de 2016 e aceito em 2 de novembro de 2016.

**Universidade Federal do Piauí, Departamento de Clinica e Cirurgia Veterinária.

***Universidade Federal do Piauí, Departamento de Clinica e Cirurgia Veterinária, Prof. DCCV - UFPI.

****Universidade Estadual Paulista Júlio de Mesquita Filho - São Paulo - UNESP/IBB - Campus de Botucatu.

Autor para correspondência: nilton_vet@hotmail.com 
a participação de outros animais reservatórios de importância epidemiológica (Cerqueira et al., 2003), como a raposa (Cerdocyon thous), o lobo guará (Chysocyon brachyurus), raposinha-do-campo (Lycalopex vetulus), cachorro-do-mato (Spheotos venaticus) e outros mamíferos marsupiais como Didelphis albiventris e D. marsupialis (Drumond; Costa, 2011).

O município de Teresina, capital do Piauí, é uma área endêmica para leishmanioses. No período de 2007 a setembro de 2011, foram registrados 171 casos de LTA no município, sendo 148 $(86,55 \%)$ da forma cutânea e $23(13,45 \%)$ da forma mucosa (S , 2011).

No ano de 2011, a maioria dos casos de LTA ocorreu no bairro Santa Teresa $(55,55 \%)$, uma comunidade rural na zona leste de Teresina, configurando um surto nessa localidade. A área apresenta baixa infraestrutura sanitária, com economia voltada para o setor primário, com elevadas altitudes e residências edificadas tanto nas áreas montanhosas como nas encostas, em meio à vegetação de floresta. Havendo muitos animais domésticos como equídeos, canídeos e felídeos nas residências.

Alguns estudos do continente europeu apontam os equinos como provável hospedeiro do parasito (Solano-Gállego et al., 2003; Rolão et al., 2005) e no Brasil um estudo experimental sugere um provável envolvimento de equídeos no ciclo da LVA (Cerqueira et al., 2003). Assim objetivou-se pesquisar infecção natural de equídeos por Leishmania sp em área endêmica de LTA de Teresina, Piauí, Brasil.

\section{Material e métodos}

A pesquisa é um estudo transversal que foi realizado no período de fevereiro a maio de 2012, no município de Teresina /PI, no bairro Santa Teresa, onde ocorreu maior número de casos humanos de LTA no período de 2010 a 2011, sob a forma de surto endêmico, tendo por base os registros do Sistema Nacional de Agravos Notificados (Sinan, 2011) do referido município.

O bairro de Santa Teresa está localizado na zona rural lestesudeste do município, $\mathrm{km} 11$ da $\mathrm{PI} 113$, a $118 \mathrm{~m}$ de altitude, e 458'08.73"S 48 38'. 31.77"O (Google Earth, 2013), pertencendo ao complexo de localidades que abrange, também, os bairros Santa Rita e Caminho Novo, sendo denominada de "Grande área da Santa Teresa". Atendida pela Equipe 0018 da Unidade Saúde da Família (USF) Santa Teresa, apresentando uma população de 1.848 habitantes (Sinan-FMS, 2011), distribuída em 436 domicílios (CCZ/Teresina, 2011).

A população de equídeos do município de Teresina, Piauí é de 680 cabeças, sendo 402 equinos, 186 asininos e 92 muares (IBGE, 2011). Entretanto, não há uma caracterização populacional das espécies por área do município. Assim sendo, a amostra populacional para este experimento foi constituída por todos os equídeos do Bairro Santa Teresa, cujos proprietários permitiram realizar a coleta do material, os quais foram informados sobre os objetivos da pesquisa e esclarecimentos conforme recomendações da Resolução do Conselho Nacional de Saúde (CNS) n 196/96. A amostra populacional constitui de 42 equídeos, sendo 31 equinos, sete asininos e quatro muares.

Antes da coleta do sangue, os animais foram submetidos a exame clínico para verificação do estado geral de saúde e observação sobre existência de lesões que fossem sugestivas de leishmaniose. Em seguida foi colhido $4 \mathrm{~mL}$ de sangue da veia jugular em tubos para coleta a vácuo com e sem EDTA para obtenção de soro e extração de DNA, respectivamente. Os soros foram acondicionados em tubos de ensaio de $5 \mathrm{ml}$ e congelados em freezer até o momento de sua utilização.

A extração do DNA do sangue dos equídeos. Inicialmente hemácias foram lisadas com tampão de lise e, em seguida, procedeu-se a extração utilizando-se kit comercial QIAamp DNA mini Kit (Quiagen) seguindo as recomendações do fabricante.

As amostras de DNA de sangue dos equídeos foram armazenadas em microtubos de $1,5 \mathrm{ml}$ e congeladas a $-20^{\circ} \mathrm{C}$. A PCR, nested PCR e sua digestão enzimática foram realizadas no Laboratório de Biologia Molecular do Departamento de Parasitologia da Universidade Estadual Paulista Júlia de Mesquita Filho/SP- Campos de Batucatu, para pesquisa de infecção por leishmânias e posterior identificação de espécie.

Para realização da "nested" PCR ITS'1 (ribossomal internal transcribed spacer 1) foram utilizadas placas (Applied Biosystems) com $4 \mu \mathrm{L}(15 \mathrm{ng} / \mu \mathrm{L})$ de DNA, dois pares de oligonucleotídeos iniciadores (primers). Na primeira fase da reação, que amplificou parte do gene ssu rDNA, utilizando os seguintes primers: R221- 5' GGTTCCTTTCCTGATTTACG 3'; e R332- 5' GGCCGGTAAAGGCCGAATAG 3', e na segunda reação os primers utilizados para amplificação foram $5.8 S$ rRNA: LITSR- 5' CTGGATCATTTTCCGATG 3' e L5.8S5' TGATACCACTTATCGCACTT 3', conforme descrito por Schönian et al, (2003).

A reação da PCR foi preparada com 12,5 $\mu \mathrm{L}$ de Go-taq (Promega), 1,0 $\mu \mathrm{L}$ de cada primer e 5,5 $\mu \mathrm{L}$ de água bidestilada conforme instruções do fabricante. A amplificação foi realizada em um termociclador (Eppendorf Mastercycler Gradient), com um ciclo inicial de $95^{\circ} \mathrm{C}$ por 3 minutos, seguido de 34 ciclos de 30 segundos a $95^{\circ} \mathrm{C}, 30$ segundos a $53^{\circ} \mathrm{C}, 1$ minuto a $72^{\circ} \mathrm{C}$ e 10 segundos a $72^{\circ} \mathrm{C}$. O produto da "nested" PCR ITS' 1 foi analisado por eletroforese em gel de agarose a $1 \%$, corado em gel red $(2 \mu \mathrm{g} / \mathrm{ml})$ e visualizado em Transluminador UV (Bioagency). Após a obtenção dos produtos de amplificação, com aproximadamente 603 bp para a primeira reação e entre 300 a 350 bp para a segunda reação, foi realizada digestão dos produtos da PCR $(10 \mu \mathrm{L})$ com enzima de restrinção HaellI, seguindo as recomendações do fabricante (Hybaid $\mathrm{GmbH}$ Heidelberg, Alemanha). A reação de digestão foi preparada com $7,3 \mu \mathrm{L}$ de água bidestilada, $2 \mu \mathrm{L}$ de tampão de reação $10 \mathrm{X}$, $0,2 \mu \mathrm{L}$ de Bovine Serum Albumin (BSA), $10 \mu \mathrm{L}$ do produto de PCR e $0,5 \mu \mathrm{L}$ da enzima de restrição, incubando-se a $37^{\circ} \mathrm{C}$ por uma hora. Como controle positivo foi utilizado produto de PCR de DNA extraído de cultura de promastigota de Leishmania (Leishamania) infantum, e como controle negativo foi utilizado água bidestilada.

Os fragmentos de restrição foram analisados em gel de agarose a 3\%, corados em gel red, visualizado em Transluminador UV e realizado a identificação das espécies de leishmânias seguindo os parâmetros estabelecidos por Schönian et al. (2003).

Foram sequenciados fragmentos de DNA, provenientes de produtos amplificados a partir das amostras de sangue de equídeos, positivos na "nested" PCR para o gênero Leishmania.

As sequências de DNA foram determinadas em sequenciador

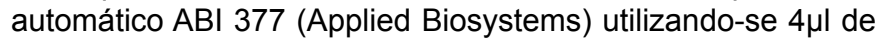
2,5X Save Money (400mM Tris- $\mathrm{HCl} \mathrm{pH} 9,0,10 \mathrm{mM} \mathrm{MgCl}$ ), $4 \mu \mathrm{l}$ de Big Dye Terminator Cycle Sequencing Ready Reaction 
Kit v 3.1 (Applied Biosystems, Foster City, CA), 3,2 pmol dos oligonucleotídeos, e $4 \mu \mathrm{l}$ do DNA genômico do parasito pesquisado a $5 \mathrm{ng} / \mu \mathrm{l}$. As reações de sequenciamento foram realizadas em termociclador Whatman Biometra (T Gradient) com os ciclos de temperatura programados para 25 ciclos de $95^{\circ} \mathrm{C}$ por $10 \mathrm{seg}, 50^{\circ} \mathrm{C}$ por $5 \mathrm{seg}, 60^{\circ} \mathrm{C}$ por 4 , com rampa de $1^{\circ} \mathrm{C} /$ seg, como recomendado pelo fabricante. Após a amplificação as amostras foram mantidas a $4^{\circ} \mathrm{C}$ até a precipitação. Para cada amostra foram utilizadas duas reações, sendo uma para o primer FORWARD e outra para o reverse.

\section{Resultados e discussão}

O grupo estudado neste trabalho foi constituído de 42 equídeos, sendo 31 equinos, quatro muares e sete asininos. Os animais não apresentavam sinais clínicos sugestivos de qualquer forma de leishamaniose e nem de outras patologias. Entretanto, 21 $(50 \%)$ reagiram positivos para Leishmania sp pela técnica do PCR (14 equinos, quatro asininos e três muares). A digestão do produto da "nested" PCR permitiu identificar sequências de DNA característico de Leishmania (Leishmania) infantum (figura 1), caracterizando a infecção como LVA. A identificação de espécie de leishmânia realizada nesta pesquisa está fundamentada em estudo por meio da digestão do produto da PCR com enzima de restrinção Hae III para a região ITS1 (Schönian et al., 2003).

O processo de digestão com a enzima Hae III foi realizado em 21 amostras, sendo que em sete não foi possível determinar a que espécie de Leishmania pertencia, devido a esse fato as amostras foram submetidas ao sequenciamento gênico.

De acordo com a análise comparativa entre os fragmentos de DNA sequenciados com os do site National Center for Biotechnology Information (NCBI), cada uma das sequências obtidas são características da espécie Leishmania (Leishmania) infantum. A sequência de bases nitrogenadas registradas no Gen Bank é compatível com a sequência determinada no sequenciamento das amostras positivas da "nested" PCR do sangue de equídeos.
A sequência de bases nitrogenadas determinada no sequenciamento gênico de amostras positivas de sangue de equídeos na "nested" PCR foi AAGTCATCCATCGCGACACGTTATGTG AGCCGTTATCCACACACGCACCCACCCCGCCAA.

Estudos registram equinos com LTA em áreas onde a LVA é endêmica. Este fato sugere a possibilidade de que os equinos possam ser infectados por Leishmania (Leishmania) infantum (Dantas-Torres et al., 2012).

Embora o cão tenha maior relevância como reservatório do parasito na cadeia epidemiológica da LVA, os equídeos poderiam também apresentar importante papel no ciclo de transmissão por servir como mais uma fonte de alimentação para os flebotomíneos, favorecendo o aumento da sua reprodução e densidade e, consequentemente, aumentando os riscos de transmissão do agente etiológico (Cerqueira et al., 2003).

Animais infectados por L. (L.) infantum sejam sintomáticos ou não, representam importante fonte de infecção para os flebotomíneos e reservatório de Leishmania, em função disso são muito importantes na transmissão da doença a animais susceptíveis (Mohammadiha et al., 2012). O fato de se relatar equídeos positivos para $L$. (L.) infantum não significa necessariamente que essa família seja reservatório do protozoário, pois para isso se faz necessário obedecer a vários critérios segundo descritos no anexo $\mathrm{G}$ do Manual de Vigilância da Leishmaniose Tegumentar Americana (2010). Entretanto, não se pode descartar a possibilidade de serem hospedeiros acidentais. Cortes (2008) relata que os hospedeiros acidentais não apresentam papel relevante na epidemiologia de uma doença, mas são importantes em função de serem capazes de introduzir ou reintroduzir uma doença numa nova região. A presença de equídeos infectados na região pode ocasionar um incremento na cadeia de transmissão da doença que mesmo podendo ser apenas um hospedeiro acidental, aumentam as fontes de alimentação de flebotomíneos.

Equídeos infectados com Leishmania (Leishmania) infantum na área sugere uma possível modificação na capacidade infectante desta espécie.

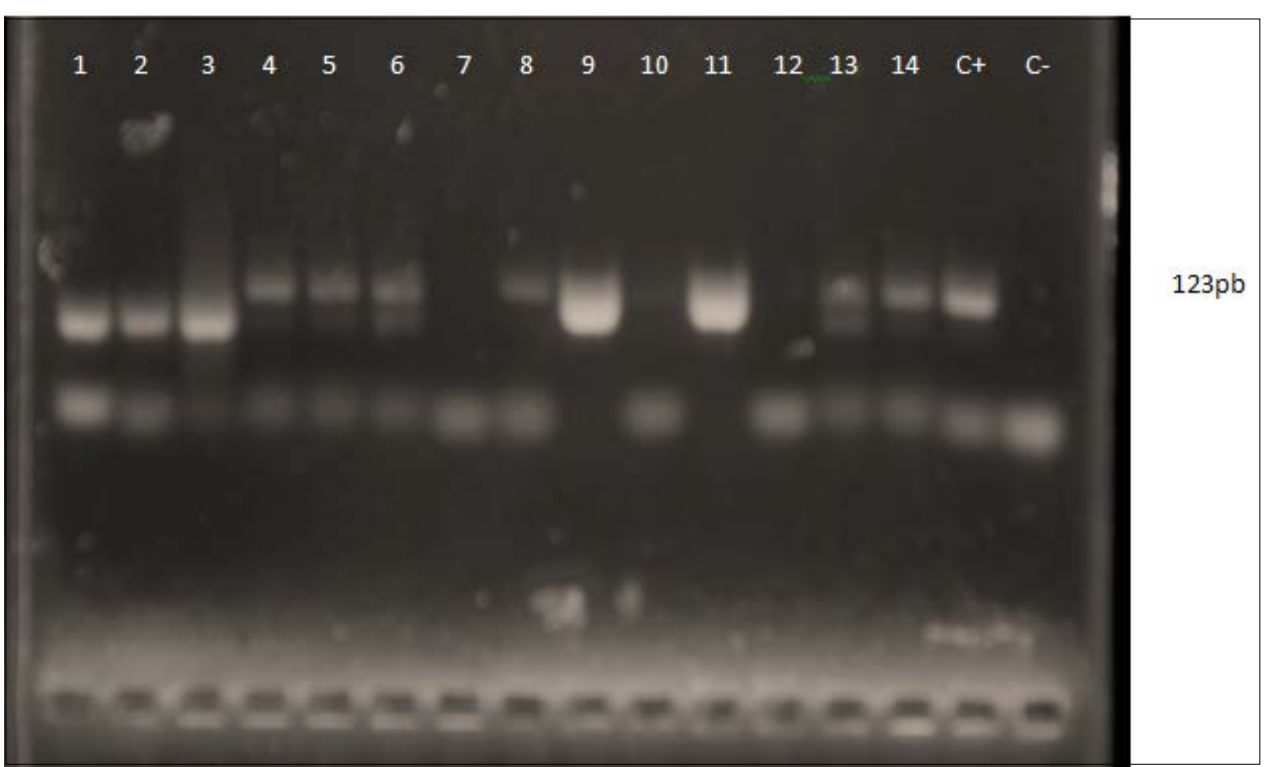

Figura 1: Análise dos produtos de digestão da PCR com enzima de restrição Hae III para a região ITS1 de Leishmania em amostras de sangue de equídeos em gel de agarose a 3\%. Linhas 4, 5, 6, 8, 13 e 14 representam fragmentos específicos para Leishmania (Leishmania) infantum a $123 \mathrm{bp}$
Em áreas endêmicas para LTA, a presença de equídeos positivos para o agente etiológico da doença, merece atenção especial, pois representam mais uma fonte de alementação para o vetor. Embora a população não seja tão numerosa, esses animais convivem no peridomicílio e há proximidade muito grande com a população tanto de tratadores como de moradores das regiões tanto rural quanto periurbana, sendo que muitos desses animais são utilizados para o trabalho e lazer.

Até o presente momento não se tem conhecimento de infecção natural por Leishmania (Leishmania) infantum em equideos no Brasil, sendo este o primeiro registro dessa ocorrência. No estado do Ceará/Brasil Cerqueira et al., 
(2003) relatam um caso de jumento infectado experimentalmente por Leishmania (Leishmania) infantum. Todos os equídeos que fizeram parte deste estudo, eram assintomáticos, o que aponta para a necessidade de realização de teste de infecção por leishmânia em área endêmica para LVA.

Na região de estudo, que é endêmica para LTA, não foi encontrada nenhuma espécie de flebotomíneo relatado na literatura como transmissor dessa forma de leishmaniose. A espécie encontrada foi Lutzomyia longipalpis, vetor de LVA. Rey (2002) relata que vários fatores contribuem para o poder infectante do flebotomíneo. Dessa forma, espécies não relatadas até o momento como vetor de determinadas espécies de leishmânia podem estar participando ao mesmo tempo do ciclo das formas tegumentar e visceral na região.

A área estudada apresenta um conjunto de características que favorecem a disseminação das leishmânias, tais como: baixo poder aquisitivo e de escolaridade da população que vive em instalações precárias, ruas sem saneamento básico e alagadiças, presença de acúmulo de lixo em muitas áreas, densa vegetação, áreas de encostas, presença de animais silvestres e domésticos envolvidos no ciclo de transmissão, contribuindo dessa forma para manutenção das leishmanioses.

\section{Agradecimento}

Agradecemos à profa ${ }^{2} r^{a}$. Hiro Goto por sua contribuição.

\section{Referências}

ALTAMIRO-ENCISO, A. J. et al. Sobre a origem e dispersão das leishmanioses cutânea e mucosa pré e pós-colombianas. História, Ciências, Saúde-Manguinhos, v.10, n. 3, p. 853-882, 2003.

ALVES, W. A. Leishmaniose visceral americana: situação atual no Brasil. Secretaria de vigilância em Saúde, Ministério da Saúde. Brasilia, DF, 2009.

BRASIL, Ministério da Saúde, Secretaria de Vigilância em Saúde, Departamento de Analise de Situação de Saúde. Brasília, 2010.

CERQUEIRA, E. J. L. et al. Inoculação experimental de Equus asinus com Leishmania chagasi Cunha \& Chagas, 1937. Rev. Soc. Bras. Med. Trop. v. 36, n. 6, p. 695-701, 2003.

CORTES, S. J. da. C., Diversidade genética da população parasitária de Leishmania em Portugal. 2008. 192 f. Tese Instituto de Higiene e Medicina Tropical - Universidade Nova de Lisboa, Lisboa, 2008.

COURTENAY, O; QUINNELL, R.J; GARCEZ, L.M; SHAW, J.J; DYE, C. Infectiousness in a Cohort of Brazilian Dogs: Why Culling Fails to Control Visceral Leishmaniasis in Areas of High Transmission. Journal of Infectious Diseases, v.186, n. 9, p. 13141320, 2002

DANTAS-TORRES, F; SOLANO-GALLEGO, L; BANETH, G; RIBEIRO, V.M; CAVALCANTI, M.P; OTRANTO, D. Canine leishmaniosis in the Old and New Worlds: unveiled similarities and differences. Trends in Parasitology, v. 28, n. 12, p. 531-538, 2012.

DRUMOND, K. O; COSTA, F. A. L, Forsty yars of visceral leishmaniasis in the state o Piauí; a review. Revista do Instituto de Medicina Tropical de São Paulo, v. 53, n. 1, p. 3-11, 2011.
A presença de animais infectados não significa que apresentarão a doença na sua forma ativa. Muitos animais conseguem controlar o parasito por longo período de tempo, permanecendo assintomáticos.

Os equídeos em meio a uma área endêmica poderiam representar mais uma fonte de sangue para o vetor das leishmanioses, contribuindo para o aumento de sua reprodução e densidade e, consequentemente, aumentando os riscos de transmissão do agente etiológico na região (Cerqueira et al., 2003).

\section{Conclusão}

Há presença de equídeos infectados com Leishmania (Leishmania) infantum em Teresina/PI.

A ausência de identificação de espécies de leishmânia causadoras de LTA sugere que os equídeos não estão envolvidos no ciclo de transmissão dessa forma de leishmaniose na região.

Os equídeos podem representar mais uma fonte de alimentação para os flebotomíneos, contribuindo para sua sobrevivência, proliferação e sua manutenção na região.

DUARTE, R. T.; MARZOCHI, F. A. O; FERREIRA, M. C. A OLIVEIRA, F. C; MENDEZ, M. R. F; GONZAGA, F. A.; Sorologia para leishmaniose em equinos no município do Rio de Janeiro, Saúde Rio - Secretaria Municipal de Saúde, 2001. Disponível em: http://www.saude.rio.rj.gov.br/cgi/public/cgilua.exe/web/templates/ $\mathrm{htm} / \mathrm{v} 2 / \mathrm{view}$.htm?from_info_index=25\&user=reader\&editionsection $\mathrm{id}=2$ \&infoid=36\#navega. [Acesso em setembro de. 2012]. 2009.

GONTIJO, C. M. F; MELO, M. N. Leishmaniose visceral no Brasil: quadro atual,desafios e perspectivas. Revista Brasileira de Epidemiologia. v. 7, n. 3, p. 338-349, 2004.

GUERIN, P. J. et al. Visceral leishmaniasis: current status of control, diagnosis and treatment and a proposed research and development agenda. The Lancet Infectious Diseases. v.2, p. 494501, 2002.

KILLICK-KENDRICK R.; RIOUX J. A. Mark-release-recapture of sand flies fed on leishmanial dogs: the natural life-cycle of Leishmania infantumin Phlebotomu sariasi. Parasitology, v. 44, p. 67-71, 2002.

MINISTÉRIO DA SAÚDE. Sistema Nacional de Agravos Notificados (SINAN). Fundação Municipal de Saúde (FMS) Teresina/PI, 2011.

MOHAMMADIHA, A. et al., Canine visceral leishmaniasis: A comparative study of real-time PCR, conventional PCR, and direct agglutination on sera for the detection of Leishmania infantum infection. Veterinary Parasitology, Amsterdam, 2012 (article in press). Parassitologia, v. 44, p. 67-71.

ORGANIZAÇÃO PANAMERICANA DE SAÚDE - OPAS. Encuentro sobre vigilancia, prevención y control de leishmaniasis visceral (LV) en el Cono Sur de Sudamérica. Foz do Iguazú, Brasil. Disponível em: http://new.paho.org/hq/index. php?option=com_docman\&task=doc_view\&gid=16961\& Itemid=, [Acesso em setembro de. 2012]. $200 \overline{9}$. 
REY, L. Bases da Parasitologia Médica. Rio de Janeiro. p. 379, 2002.

ROLÃO, N. et al. Equine infection with Leishmania in Portugal. Parasite,v. 12, p. 183-186, 2005.

SACKS D.; KAMHAWI S. Molecular aspects of parasite-vector and vector-host interactions in leishmaniasis. Annu Revista Microbiologia. v. 55, p. 453-83. 2001.

SCHONIAN G, NASEREDDIN A, DINSE N, SCHWEYNOCH C, SCHALLIG H.D, PRESBER W, JAFFE C.L. PCR diagnosis and characterization of Leishmaniain local and imported clinical samples. Diagn Micro-biol Infect Dis 47: 349-358. 2003.
SOLANO-GÁLLEGO, L. et al. Cutaneous leishmaniosis in three horses in Spain. Equine Veterinary Journal, v. 35, p. 320-323, 2003.

SUNDAR, S., RAY, M. Advances in the treatment of leishmaniasis. Current Opinion on Infectious Diseases, 15: 593-8. 2002.

WORLD HEALTH ORGANIZATION. Working to overcome the global impact of neglected tropical diseases: First WHO report on neglected tropical diseases. 2010 [Acessado em nov. 2012]. Disponível em http://www.who.int/neglected_diseases/ 2010report/ NTD_2010report_embargoed.pdf.2010 